ARTICLE OPEN

Check for updates

\title{
A model study on controlling dealloying corrosion attack by lateral modification of surfactant inhibitors
}

\author{
Shova Neupane $\mathbb{D}^{1,11}$, Nicolás A. Rivas ${ }^{1}$, Patricia Losada-Pérez ${ }^{1,2}$, Jan D’Haen ${ }^{1}$, Heshmat Noei ${ }^{3}$, Thomas. F. Keller $\mathbb{D}^{3,4}$, \\ Andreas Stierle $\mathbb{D}^{3,4}$, Michael Rudolph ${ }^{5}$, Andreas Terfort $\mathbb{D}^{5}$, Oscar Bertran $\mathbb{D}^{6}$, Daniel Crespo $\mathbb{D}^{6,7,8}$, Anton Kokalj $\mathbb{D}^{9}$ and \\ Frank Uwe Renner (iD) $1,10 \times$
}

Detrimental corrosion is an ever-concerning challenge for metals and alloys. One possible remedy is to apply organic corrosion inhibitors. Despite progress in molecular assembly and inhibitor research, better mechanistic insight on the molecular level is needed. Here we report on the behavior of well-defined artificial molecular interfaces created by micro-contact printing of thiolinhibitor molecules and subsequent backfilling. The obtained heterogeneity and defects trigger localized dealloying-corrosion of well-defined $\mathrm{Cu}_{3} \mathrm{Au}$ surfaces. The stability of applied inhibitor molecules depends on alloy surface morphology and on intermolecular forces of the molecular layers. On extended terraces, dealloying preferentially starts at the boundary between areas composed of the two different chain-length inhibitor molecules. Inside of the areas hardly any nucleation of initial pits is visible. Step density strongly influences the morphology of the dealloying attack, while film heterogeneity avoids cracking and controls molecular-scale corrosion attack. The presented surface-science approach, moreover, will ultimately allow to verify the acting mechanisms of inhibitor-cocktails to develop recipes to stabilize metallic alloy surfaces.

npj Materials Degradation (2021)5:29; https://doi.org/10.1038/s41529-021-00169-2

\section{INTRODUCTION}

Wet corrosion and laterally heterogeneous molecular interfaces both pose severe challenges for characterization ${ }^{1}$, which becomes a pivotal challenge to further advance materials stability. On the one hand, alloy design provides a possible anti-corrosion strategy from within the material. Inhibitor molecules, on the other hand, are added to the solution side of a corrosion environment. Various organic inhibitors are used, in part, because of their "autophobic" behavior and capacity to form self-assembled monolayers ${ }^{2}$ (SAMs). These amphiphilic assemblies are formed by spontaneous adsorption, and such surfactant inhibitors have been widely employed ${ }^{2-5}$. However, passivation as well as inhibitors can lead to dangerous localized pitting when the protection finally breaks down even at one single spot $^{6,7}$. Dealloying of binary noble metal alloys was among the first studied basic scenarios in corrosion science ${ }^{8-10}$. Dealloying is also a process that may dangerously lead to cracking failure under stress ${ }^{11}$. For pristine simple $\mathrm{Cu}-\mathrm{Au}$ alloys in acidic electrolytes, limited initial Cu dissolution occurs below a critical potential $\left(E_{c}\right)$, thereby forming a noble $\mathrm{Au}$ layer enabled by high surface diffusion in electrolytes ${ }^{9,12}$. Later, the thin passive layer of Au on the surface breaks down above $E_{c}$ and thicker nanoporous gold (np-Au) films are formed. Technically, this process and np-Au are used for supercapacitors, catalysis, or biosensors ${ }^{13}$. Interestingly and importantly, the dealloying formation of $\mathrm{np}-\mathrm{Au}$ is accompanied by volume shrinkage ${ }^{14}$. While clean alloy surfaces show a laterally very homogeneous dealloying process ${ }^{9,12}$, an adsorbed continuous inhibitor film finally triggers a heterogeneous, localized corrosion behavior developing micrometer-sized nanoporous pits and initial cracks on the surfaces ${ }^{15}$. Detailed understanding of the microscopic origin of such inhibitor breakdown and the correlation of the initiation sites with the nature of the film's defects offer an enormous potential of exploiting synergistic effects in applications of molecular inhibitor mixtures and additive cocktails. Microcontact printing $(\mu \mathrm{CP})^{16-20}$ to create pre-formed inhibitor film patches enables to study artificial, laterally complex mixed-alkanethiol SAMs, including controlled boundaries between neighboring areas of inhibitor molecules (different or not) ${ }^{21}$. This approach uniquely links detailed atomic-scale structural and compositional knowledge of created hybrid organic inhibitor films to the macroscopic electrochemical surface stability and corrosion behavior. A variety of molecular arrangements can be created through a subsequent application of $\mu \mathrm{CP}$ steps and backfilling by subsequent immersion. Knowledge can be eventually transferred from the here described dealloying process to a wider spectrum of materials and corrosion scenarios. Here we focus on the influence of the complex SAMs as well as on the surface morphology of the initial substrates. We selected stable, low-index $\mathrm{Cu}_{3} \mathrm{Au}(001)$ substrates, which exhibit low corrosion attack in the presence of thiols ${ }^{15,22}$ (while $\mathrm{Cu}_{3} \mathrm{Au}(011)$ shows the highest attack ${ }^{6}$ ). The artificial creation and control of the number and the nature of molecular defect sites are key to further our understanding of a wide range of molecular membrane and film behavior which is ultimately essential in various fields from interface engineering and surface chemistry to membrane physics.

\section{RESULTS AND DISCUSSION}

\section{Surface pre-characterization and electrochemistry}

To distinguish printed and backfilled areas, we selected longer octadecanethiol $\left(\mathrm{C}_{18}-\mathrm{SH}\right)$ and shorter butanethiol $\left(\mathrm{C}_{4}-\mathrm{SH}\right)$ compounds.

\footnotetext{
${ }^{1}$ Institute for Materials Research (IMO), Hasselt University, Diepenbeek, Belgium. ${ }^{2}$ Experimental Soft Matter and Thermal Physics group (EST), Université Libre de Bruxelles (ULB), Brussels, Belgium. ${ }^{3}$ Centre for X-ray and Nano Science CXNS, Deutsches Elektronen-Synchrotron DESY, Hamburg, Germany. ${ }^{4}$ Physics Department, University of Hamburg, Hamburg, Germany. ${ }^{5}$ Institute of Inorganic and Analytical Chemistry, Goethe-University, Frankfurt am Main, Germany. ${ }^{6}$ Department of Physics, Universitat Politècnica de Catalunya, Barcelona, Spain. ${ }^{7}$ Barcelona Research Center in Multiscale Science and Engineering, Universitat Politècnica de Catalunya, Barcelona, Spain. ${ }^{8}$ Institute of Energy Technologies, Universitat Politècnica de Catalunya, Barcelona, Spain. ${ }^{9}$ Department of Physical and Organic Chemistry, Jožef Stefan Institute, Ljubljana, Slovenia. ${ }^{10}$ IMEC vzw. Division IMOMEC, Diepenbeek, Belgium. ${ }^{11}$ Present address: Institut de Recherche de Chimie ParisTech- CNRS, Paris, France. ${ }^{\circledR}$ email: frank.renner@uhasselt.be
} 

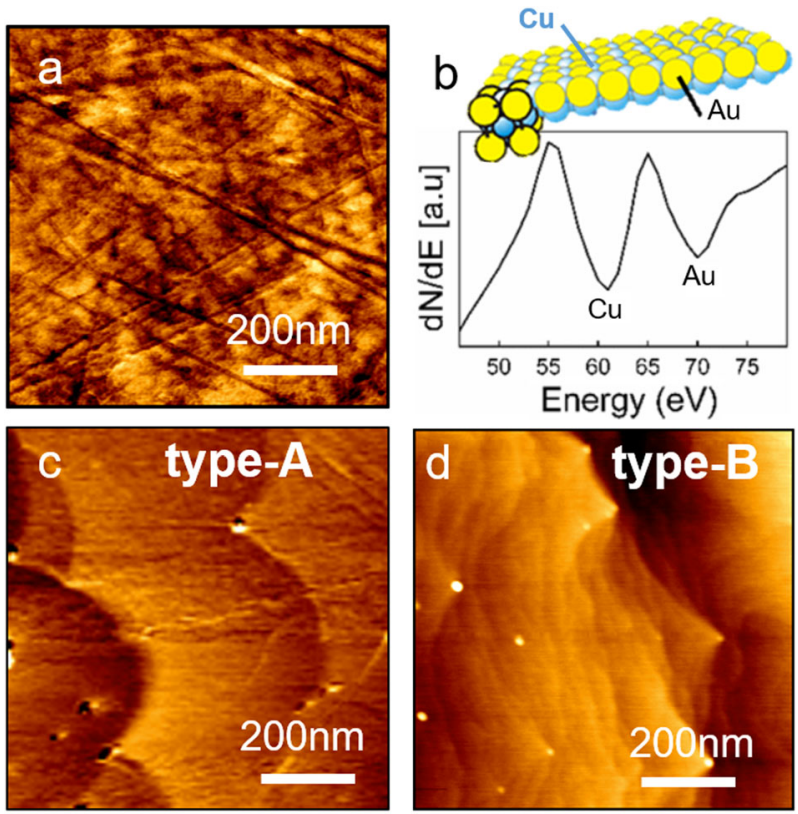

$0 \mathrm{~nm}$

$3 \mathrm{~nm}$

Fig. 1 Surface preparation. a AFM image of a $\mathrm{Cu}_{3} \mathrm{Au}(001)$ surface after polishing (as received) before UHV preparation. b Auger spectrum of a UHV-prepared $\mathrm{Cu}_{3} \mathrm{Au}(001)$ surface. c AFM images of $\mathrm{Cu}_{3} \mathrm{Au}(001)$ surfaces type-A (large atomic terraces) and (d), type-B (small atomic terraces) after UHV preparation.

Most organic inhibitor molecules have a comparable size relative to typical roughness values of metal surfaces. Mechanistic studies of initial corrosion at atomic or molecular-scale thus ideally require flat, clean, and well-defined surfaces, i.e., a state-of-the-art surface science approach. Bare alloy surfaces were here prepared by sputtering with $\mathrm{Ar}^{+}$and annealing cycles in ultra-high vacuum (UHV). After mechanical polishing but before UHV preparation, the $\mathrm{Cu}_{3} A$ u surfaces showed the typical roughness and polishing lines (Fig. 1a). During UHV preparation, the surface composition was verified by Auger Electron Spectroscopy (AES, Fig. 1b) and the structural integrity by Low-Energy Electron Diffraction (LEED, Supplementary Fig. 1). The prepared surfaces show significant differences in surface morphology before and after UHV surface preparation, but also between individual UHV preparations. Figure 1c represents a set of typical samples after a higher number of sputtering cycles. The atomic terraces are large, with an average lateral width of $500 \mathrm{~nm}$. Such sample surfaces will be hereafter referred to as type-A samples.

In general, the UHV pretreated surfaces were locally homogeneous and atomically flat. The surface morphology was verified by AFM and is represented in 5-10 imaged spots (Supplementary Fig. 2). Following this pre-characterization, the second set of samples with smaller terrace sizes, typically obtained after a smaller number of sputtering cycles, was selected as type-B surfaces. The average terraces on type-B samples (Fig. 1d) were consistently smaller, exhibiting average widths below $100 \mathrm{~nm}$. AFM images showed white spots that we ascribe to small atomic islands on the UHV cleaned $\mathrm{Cu}_{3} \mathrm{Au}(100)$ surface. SEM-EDX revealed that they are gold pinned islands or particles (Supplementary Fig. 3). These small islands or particles appeared on the surface after annealing at $750^{\circ} \mathrm{C}$ due to Au segregations on the surface. Potentiodynamic sweeps and cyclic voltammetry measurements (CV) on such surfaces were performed on multiple samples where these gold islands or particles in different densities were found to not alter the CV behavior. Using an intermediate mild dealloying step the additional islands could be further removed as we showed in the previous work ${ }^{22}$. After UHV cleaning of the sample
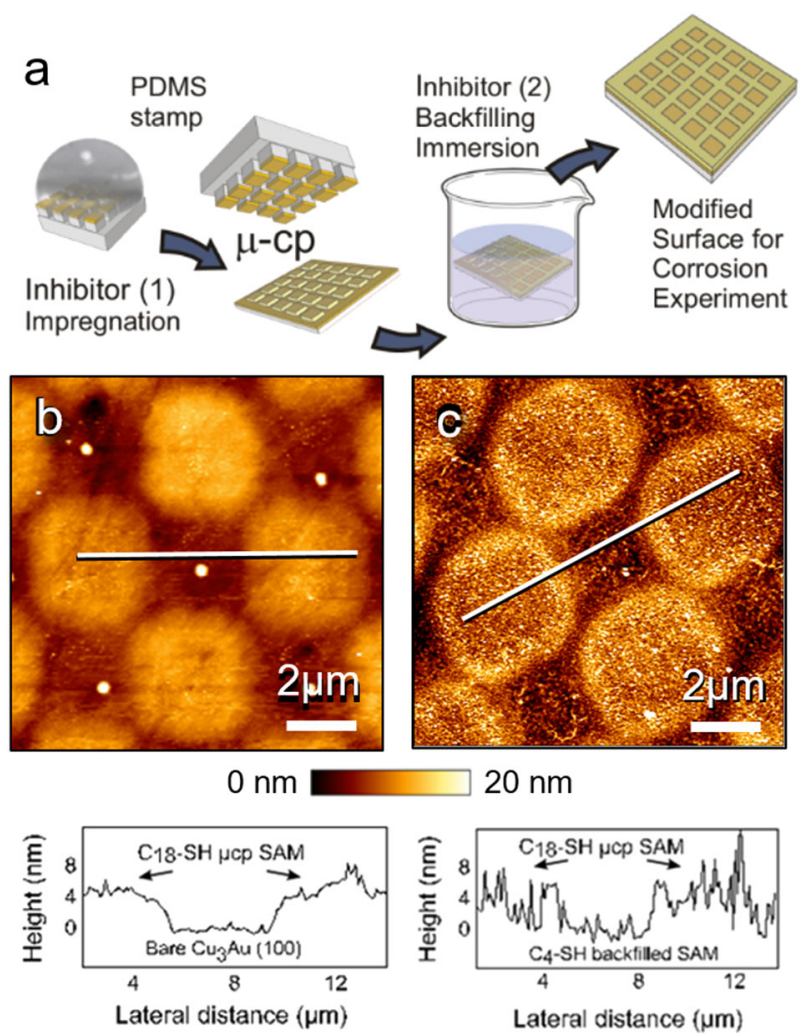

Fig. 2 Experimental approach. a Sketch of micro-contact printed ( $\mu \mathrm{CP}) \mathrm{C}_{18}$-SH SAM and $\mathrm{C}_{4}$-SH backfilled on a cleaned $\mathrm{Cu}_{3} \mathrm{Au}(001)$ surface. AFM images of a $\mathrm{Cu}_{3} \mathrm{Au}(001)$ surface, including the corresponding height profiles (b) after $\mu \mathrm{CP}$ of $\mathrm{C}_{18}$-SH and (c) after additional backfilling of $\mathrm{C}_{4}-\mathrm{SH}$.

surface, micro-contact printing with $\mathrm{C}_{18}-\mathrm{SH}$ was applied (Fig. 2a, Supplementary Fig. 4). Figure $2 \mathrm{~b}$ displays one resulting square $\mu \mathrm{CP}$-pattern of $\mathrm{C}_{18}$-SH on a type- $\mathrm{ACu} \mathrm{Cu}_{3} \mathrm{Au}(001)$ surface. The initially free surface in-between the $\mathrm{C}_{18}$-SH square patches was backfilled by immersion with $\mathrm{C}_{4}-\mathrm{SH}$ (Fig. 2c). The surface roughness after solution backfilling is slightly increased. Concerning the sample, the used $\mu C P$ stamps were smaller than the samples. Thus, printing resulted in two well-differentiated regions, i.e., a $\mathrm{C}_{18}-\mathrm{SH}$ square pattern backfilled with $\mathrm{C}_{4}$-SH and a separate region only covered with $\mathrm{C}_{4}$-SH next to it.

Typically single potentiodynamic sweeps were performed. For a type-A sample, such a sweep is shown in Fig. 3. Some initial $\mathrm{Cu}$ dissolution may still take place at around $+0.40 \mathrm{~V}$ (as shown in the inset of Fig. 3 and Supplementary Fig. 5) but overall no major $\mathrm{Cu}$ dissolution is observed. With the surface adsorption of thiol molecules the surfaces are passivated with an ultrathin film of $\mathrm{Au}$ already after immersion, and clearly, before we reach the onset of breakdown and start of massive $\mathrm{Cu}$ dissolution at the critical potential ${ }^{15,23}$. Above $0.8 \mathrm{~V}$, known as critical potential $\left(E_{c}\right)$ in this system, the current increases dramatically, indicating that (bulk) dealloying takes over ${ }^{12}$. In the printed region, the border between the print-patch patterns of $\mathrm{C}_{18}-\mathrm{SH}$ and the backfilled $\mathrm{C}_{4}$-SH areas appeared with localized initial dealloying pits highlighted in Fig. 4. The molecule architecture and molecular (dis)order play thus clearly a decisive role in corrosion inhibition. Intermolecular, van der Waals interactions mediate the arrangement between the alkyl chains. SEM images presented in Fig. 4a-c show the pores formed by initial $\mathrm{Cu}$ dissolution decorating the $\mathrm{C}_{18}$-SH print-patch border region. The area inside the $\mu \mathrm{CP} \mathrm{C}_{18}-\mathrm{SH}$ squares is fully protected, and also, backfilled $\mathrm{C}_{4}$-SH regions appear without dissolution pits. Nevertheless, the $\mathrm{C}_{4}$-SH regions lie slightly deeper 
and display clear differences in surface morphology with some visible small island structures (Fig. 4b, Supplementary Fig. 5). This reflects the comparatively higher molecular mobility and the associated slightly higher amount of very initial $\mathrm{Cu}$ dissolution inside the short-chain areas. Both, printed patches as well as films created by only immersion-adsorption, typically exhibit sub-

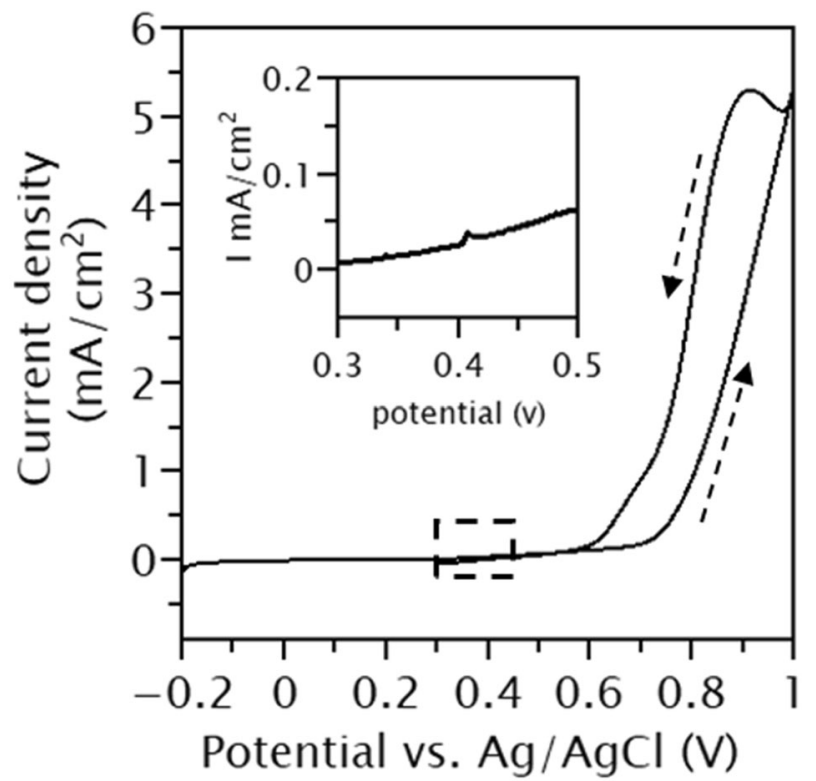

Fig. 3 Cyclic voltammetry at $5 \mathrm{mV} / \mathrm{s}$ in $0.1 \mathrm{M} \mathrm{H}_{2} \mathrm{SO}_{4}$ of a $\mathrm{Cu}_{3} \mathrm{Au}$ (100) surface modified with $\mu \mathrm{CP}-\mathrm{C}_{18}-\mathrm{SH}$ and backfilled with $\mathrm{C}_{4}$-SH solution. Hysteresis on the reverse scan after reaching the critical potential indicates initial dealloying pits and cracks. Inset: Range of initial $\mathrm{Cu}$ dissolution. domains of a few tens of nanometers in diameter ${ }^{24,25}$. Important to note, the small sub-domains inside one patch, printed or backfilled, do not become active as dissolution sites. Indeed, $\mathrm{C}_{18^{-}}$ $\mathrm{SH}$ SAMs were created by micro-contact printing, while $\mathrm{C}_{4}-\mathrm{SH}$ SAMs were formed by solution adsorption over a longer period of several hours. Dealloying and nanoporosity formation initiate at the boundary of printed and backfilled patches. Small pits or pores appear merely following the square boundaries due to initially localized dealloying along these boundaries. The conceptual illustration in Fig. 4d shows the possible molecular orientations on the print patch boundary regions and a highlighted sketch (Fig. 4e) shows the molecular orientation at the boundary. In addition, some pattern boundary regions at different spots on the surfaces clearly display two adjacent rings of increased dealloying initiation as displayed in the AFM image in Fig. 4f and Supplementary Fig. 6 . The junction area between two molecular patches is about $800 \mathrm{~nm}$ wide. Interestingly, the inside area of around $300 \mathrm{~nm}$ between the outer borders is still better protected. With further dealloying by subsequent cycles (from -0.2 to $0.85 \mathrm{~V}$ ) the dealloying pores which initiated at the boundary expand towards the full backfilled $\mathrm{C}_{4}-\mathrm{SH}$ area after two more cycles (Fig. $4 \mathrm{~g}$ and Supplementary Fig. 6). The surrounding $\mathrm{C}_{18}-\mathrm{SH}$ regions are still protected. Thus, an array of artificial defects within a monolayer of inhibitor molecules has been created in a wellcontrolled approach and has guided the initiation and initial progress of dealloying corrosion along with the respective defect pattern. The initial dealloying on flat type-A surfaces (large atomic terraces) only feels a minor disturbance by atomic steps (Fig. 5 and Supplementary Fig. 7).

\section{Molecular simulations and post-dealloying characterizations}

With today's possibilities in computing, molecular and atomic-scale simulation of physical properties and behavior will become increasingly important. The layer boundaries are complex (Fig. 5a) and often the detailed formation sequence is unknown. During force-
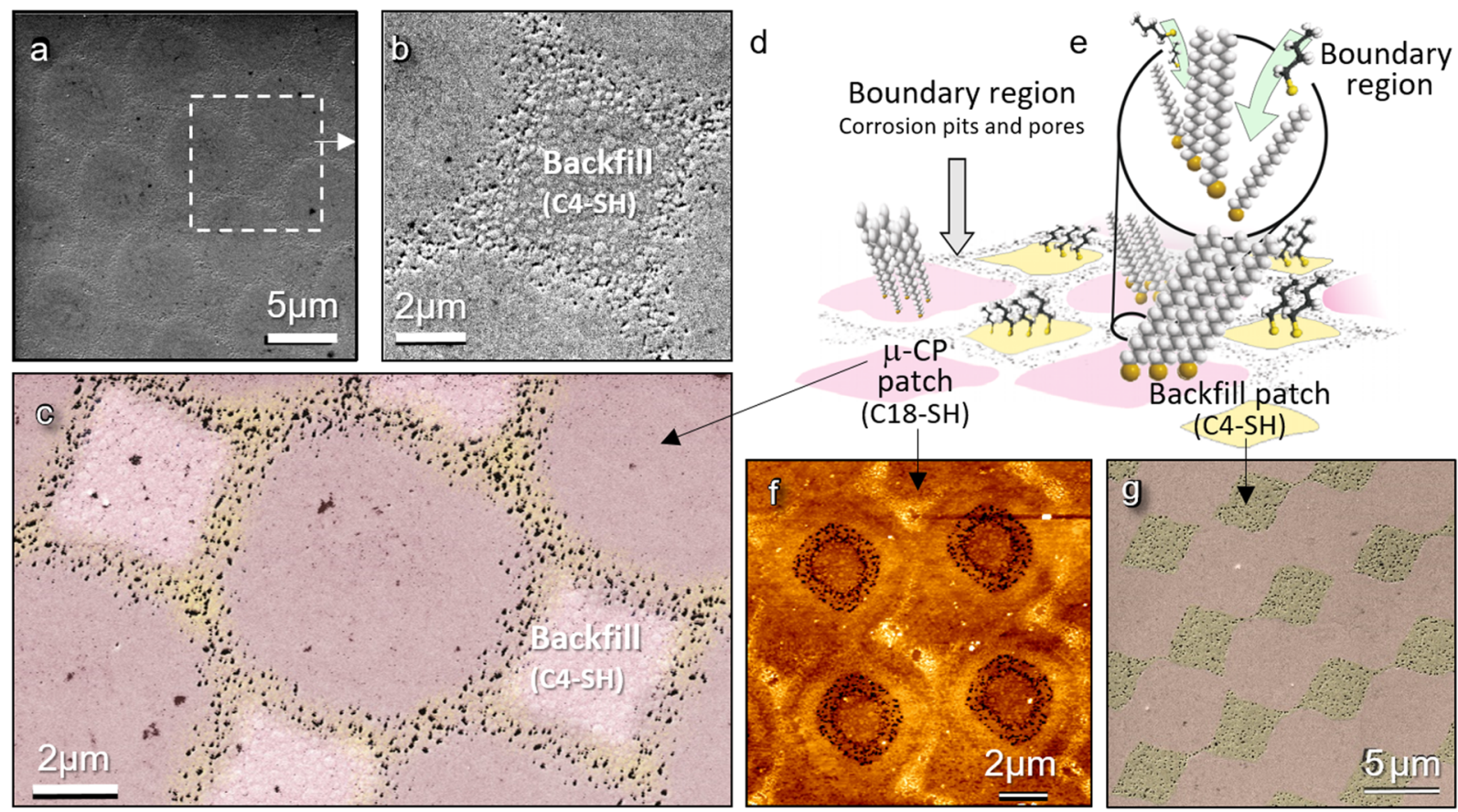

Fig. 4 Localized initial dealloying along artificial SAM patch boundaries. a SEM image of $\mu C P-\mathrm{C}_{18}-\mathrm{SH} / \mathrm{C}_{4}-\mathrm{SH}$ modified type-A surface after dealloying. b Zoom-in to initial dealloying region, contrast-enhanced SEM image. c Color-modified SEM image showing localized initial dealloying along artificial SAM boundaries. d Illustration representing initially localized dealloying, with (e) highlighting of the interface region. f Occasionally observed double-ring pit area, AFM image. $\mathbf{g} \mathrm{SEM}$ image, localized dealloying is restricted to $\mathrm{C}_{4}$-SH patches after additional cycles. 
field, molecular dynamics simulations of stability and behavior of octadecanethiol patches on $\mathrm{Au}$, the density of an initial thiol array was reduced to reach a stable configuration (Fig. 5b). Adsorbed thiols

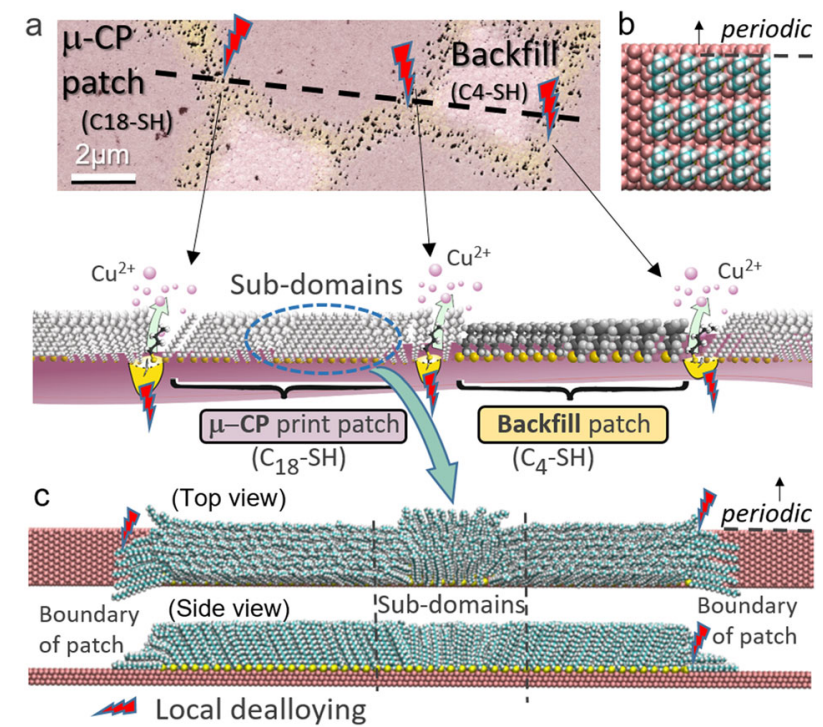

Fig. 5 Simulation and interpretation of SAM formation at boundaries. a Color-modified SEM image showing localized initial dealloying along artificial SAM boundaries and sketch of inhibitor breakdown at boundaries. b Initial distribution of the thiol molecules on the simulated surface. c Simulated patch of thiol molecules on an $\mathrm{Au}(111)$ surface. The sample is periodic in the shortest direction (i.e., $y$-direction). on $\mathrm{Cu}_{3} \mathrm{Au}$ result in Au segregation of a few atomic layers of $\mathrm{Au}^{15}$. This scenario is a good approximation of our setting. After $1 \mathrm{~ns}$, the molecules on the free sides of the thiol patch fell along the $x$ direction (according to Fig. $5 \mathrm{c}$ ) toward the Au surface. Neighboring molecules fell towards them, quickly forming an (expected) angle around $26^{\circ}$ from the surface normal. In the center of the shown simulated patch, a sub-domain was created with molecules tilted in the $y$-direction but keeping the same angle with the surface normal (Fig. 5c). While the sub-domains and their (smooth) boundaries were not visibly active during our experiments, the outer patch borders after backfilling are. Earlier results on the same-molecule backfilling ${ }^{21}$ on pure $\mathrm{Au}$ also revealed a different nature of the outer patch borders in comparison to internal sub-domains of the individual print patches. The consecutive steps of printing and backfilling are thus important to obtain the differently ordered arrangements (defects) around the initial print patches. Our ongoing simulation results, therefore, directly point to the mechanisms creating the special nature of the patch borders in the sequential formation of the heterogeneous organic film.

A few large (crack-free) circular dealloying pits with a diameter of about $10 \mu \mathrm{m}$ also appeared on low step-density type-A samples, otherwise showing the controlled boundary attack of Fig. 4. This is remarkable because, for conventional inhibitor SAMs on type-A surfaces, smaller crack pits were always observed ${ }^{6,15}$. These cracks exhibit a deeper pit volume (Fig. 6, Supplementary Fig. 8). Differently from the well-defined corrosion attack along the artificially-made inhibitor boundaries described above, we also observe, exclusively on type-B surfaces, corrosion attack characterized by a low number of much larger circular porous pits distributed over the surface at a few arbitrary sites. Figure 6 compares the observed individual larger dealloying pits on large-terrace type-A and small-terrace type-B $\mathrm{Cu}_{3} \mathrm{Au}(001)$ surfaces, including the respective focus ion beam (FIB) cross-sections of selected pits. The printed area is typically smaller
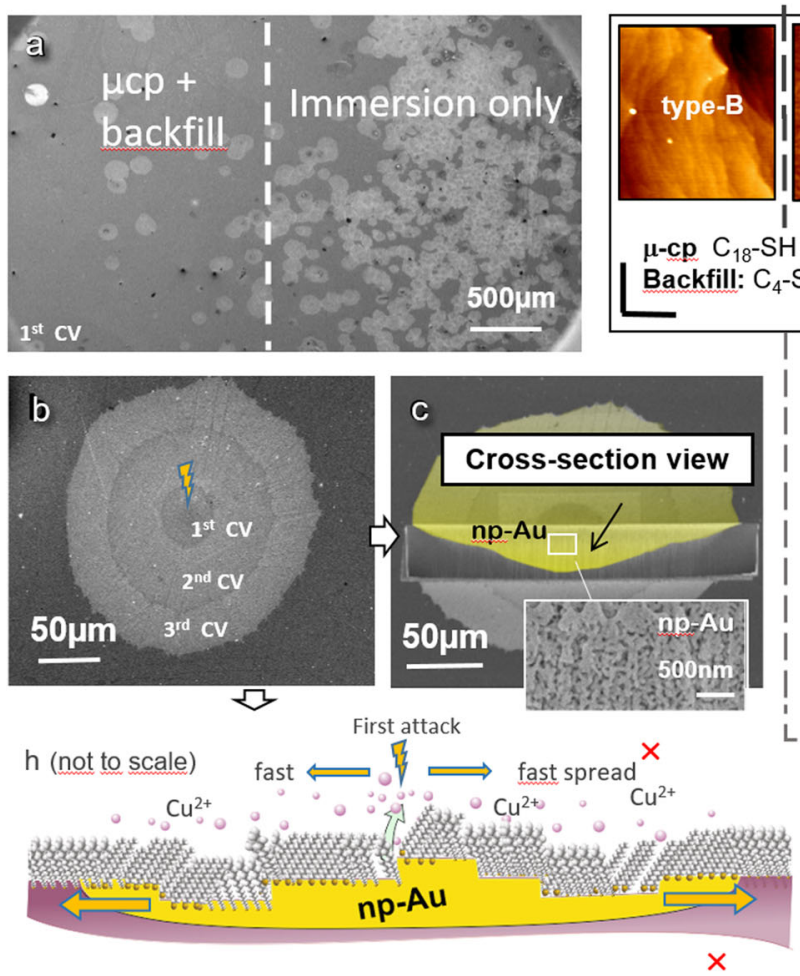
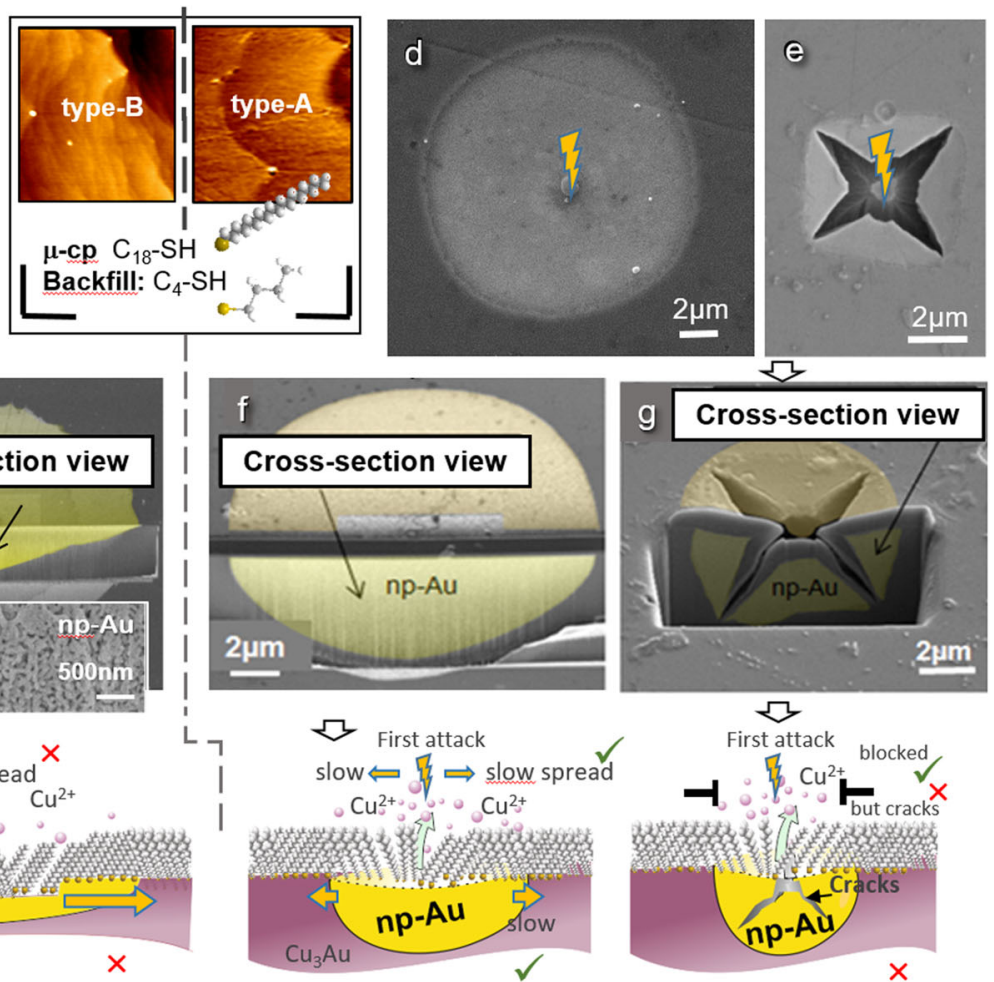

Fig. 6 Localized dealloying pits on alkanethiol modified surfaces. a SEM images of type-B high-step-density surfaces: circular pits on printed $\mathrm{C}_{18}-\mathrm{SH}+$ back-filled $\mathrm{C}_{4}-\mathrm{SH}$, as well as only $\mathrm{C}_{4}-\mathrm{SH}$ immersed areas. b Dealloying pit after $3 \mathrm{CVs}$ and (c) its cross-section showing np-Au interior. d Type-A low-step-density $\mathrm{Cu}_{3} \mathrm{Au}(001)$ surfaces exhibiting circular pits. e Star-shaped dealloying pit. $\mathbf{f}$, $\mathbf{g}$ Respective cross-sections for circular and star-shaped pits. $\mathbf{h}$ Sketch of inhibitor breakdown within inhibitor-covered areas for two cases of inhibitor-modified corrosion progress (not to scale). 
than the substrate, and also local variations of the printing quality exist and thus result in a final library surface after dealloying enabling us to read and decipher different aspects of working inhibitor mechanisms. For type- $\mathrm{B} \mathrm{Cu}_{3} \mathrm{Au}(001)$ surfaces with small terrace size (i.e., high density of surface steps, Fig. $6 a-c)$ we always observed the larger circular pits developing in a very flat ("pancake") morphology. For type-B surfaces, the print-patch borders did not show preferential attack, which may be either due to a less efficient printing process or due to a higher number of intra-layer molecular defects with high substrate step density. Interestingly, the printed-backfilled region exhibits always fewer circular dealloying pits compared to the only immersed area (Fig. 6a). For all pits, each CV increases the already formed dealloyed circles by additional radial growth and also produces few additional circular pits. The coexistence of patterned and solution backfilled thiol SAM, i.e., the subsequent growth on a (pre-nucleated) pre-patterned area, increases the final stability of the alkanethiol SAMs and avoids molecular initiation defects for corrosion attack. Therefore, regions containing pre-patterned alkanethiol SAM backfilled with alkanethiol molecules display better corrosion protection with a lower number of emerging pits than the only solution immersed (single-step) alkanethiol SAMs. The pit radius along the type-B surface was typically three to five times larger than the spread of nanoporous into the bulk (Fig. 6b-e). Clearly, for a high step density, the stability of the organic surfactant inhibitors is thus limited by the underlying surface morphology.

For comparison, Fig. $6 \mathrm{~d}$ displays a representative pit that appeared in small numbers on type-A samples with corrosion following the artificially made inhibitor boundaries described above. The pit shows no crack and a slightly anisotropic growth. Finally, Fig. 6e shows a typical crack-pit as it appears on immersed flat surfaces homogeneously covered by an inhibitor. The crack-pit then develops in the largest possible volume of a half-sphere with a surface radius equal to the penetration. The pit growth along the surface is thus entirely limited by the bulk progression of the forming nanoporosity under-growing the inhibitor-stabilized surface at the front of progression. Cracks due to volume reduction during the formation of nanoporosity ${ }^{13}$ thus appear if the local pit growth along the surfaces is of the same order than normal to the surface as evidenced by FIB-cut cross-sections (Fig. 6c, f, g, and Supplementary Fig. 8). Cracking can thus be avoided if the surface progression is slightly enhanced and not entirely blocked. All pits show homogenous nanoporosity all over the affected pit volume. While on the large-terrace type-A surfaces both, crack-pits and crack-free (but still large-volume) circular pits are eventually observed, type-B surfaces always only corrode via the formation of flat low volume circular pits ("pancake-type") growing much faster along the surface than penetrating the bulk. The spread and kinetics of the attack along the materials surface do decisively control the final morphology and cracking behavior. Materials degradation depends here largely on the defect structure in the molecular adsorbate film which is very different along patch boundaries but may also be influenced inside a homogeneous area by introducing minority additives. Surfactant corrosion inhibitors are widely used on a variety of different alloys ${ }^{26}$. Knowledge about the molecular-scale influence of inhibitor stability and the very first atomic-scale attack can be therefore eventually transferred from the here described dealloying process to a wider spectrum of materials and corrosion scenarios.

The exact (local) composition of extended inhibitor layers as well as the substrate morphology thus considerably influence the corrosion progression. By artificially creating defects within the inhibitor film using sequential micro-contact printing and backfilling, we were able to control and guide the initial corrosion attack. An ultimately dangerous side of corrosion protection becomes apparent in the form of surface cracks appearing only for the case of the most effective corrosion protection where the inhibitor-modified surface resists a spreading dealloying pit. Artificial heterogeneity in the layer can mitigate surface cracking by increasing dealloying along domain patch boundaries, i.e., by effective control of corrosion-attack sites down to the molecular scale. For a high step density, the stability of the organic surfactant inhibitors is limited by the underlying surface morphology. The molecular understanding is key for the design of inhibitor cocktails employing a control of surfactant adsorption, nucleation, and inhibitor film growth. Our approach of subsequently building up a laterally modified surfactant film can be employed for a larger number of molecules and a broad range of applications from surface chemistry to membrane physics and interface engineering.

\section{METHODS}

\section{Sample preparation}

Single crystals of $\mathrm{Cu}_{3} \mathrm{Au}(001)$ were purchased from MaTeck $\mathrm{GmbH}$, Germany. The alloy samples are one-side polished disks (roughness $<0.01 \mu \mathrm{m}$ ) with a diameter of $8.0 \mathrm{~mm}$, a thickness of $2.5 \mathrm{~mm}$, and surface orientation accuracy $<0.1^{\circ}$. The polished $\mathrm{Cu}_{3} \mathrm{Au}(001)$ alloy surfaces were sequentially cleaned by $\mathrm{Ar}^{+}$sputtering $\left(1.0 \mathrm{keV}\right.$ energy) at $1.0 \times 10^{-6} \mathrm{mbar}$ and annealing at $750^{\circ} \mathrm{C}$ in Ultrahigh Vacuum (UHV) in order to obtain clean and (locally) inherently flat surfaces. Auger electron spectra (AES) were recorded in UHV for $\mathrm{C}(272 \mathrm{eV})$ and $\mathrm{Cu}(778,842,922$, and $66 \mathrm{eV})$ and for $\mathrm{Au}$ at low energy $(74 \mathrm{eV})$ before and after each sputter-annealing cycle. After several sputter-annealing cycles and AES characterization, low energy electron diffraction (LEED) patterns were recorded at different energies. The sample preparation was performed at DESY Nanolab, Hamburg, Germany.

1-Butanethiol $(\geq 99 \%)$ was purchased from ACROS organic, and 1octadecanethiol $(\geq 98 \%)$ was purchased from Sigma Aldrich. Absolute ethanol ( $\geq 99.85 \%)$, 2-propanol ( $\geq 99.7 \%)$, and sulfuric acid $(95 \%)$ were obtained from VWR Prolab Chemicals, and Milli-Q water from Arium Pro-VF pore size $0.2 \mu \mathrm{m}$ (Sartorius Stedim Biotech, France). All the chemicals were used without further purification. All alkanethiol ethanolic solutions were prepared at a concentration of $1 \mathrm{mM}$. Micro-contact printing $(\mu \mathrm{CP})$ of octadecanethiol $\left(\mathrm{C}_{18}-\mathrm{SH}\right)$ onto the $\mathrm{Cu}_{3} \mathrm{Au}(001)$ surfaces was carried out with the help of a PDMS stamp (Fig. 3) bearing well-defined geometry $(5 \times$ $5 \mu \mathrm{m}$ squares), following reported $\mu \mathrm{CP}$ procedures. After $\mu \mathrm{CP}$, the patterned surfaces were backfilled by immersion for $\sim 22 \mathrm{~h}$ in $1 \mathrm{mM}$ ethanolic solutions of butanethiol $\left(\mathrm{C}_{4}-\mathrm{SH}\right)$. After the surface modifications, samples were thoroughly rinsed with ethanol and dried with $\mathrm{N}_{2}$ gas.

\section{Electrochemical dealloying and post dealloying characterizations}

Dealloying was carried out in $0.1 \mathrm{M} \mathrm{H}_{2} \mathrm{SO}_{4}$ using a potentiostat (Autolab potentiostat model no. PGSTAT128N with NOVA 2.1 software) connected to a three-electrode electrochemical cell especially designed for in-situ electrochemical measurements in combination with atomic force microscopy $(\mathrm{AFM})^{27}$. A ceramic ring with a thin deposited Au film employed as a counter electrode and a homemade $\mathrm{Ag} / \mathrm{AgCl}(3.0 \mathrm{M} \mathrm{KCl}$ calibrated with SHE at $0.210 \mathrm{~V}$ ) micro reference electrode was used as a reference electrode $^{28}$. All potentials mentioned in this paper are referred to $\mathrm{Ag} / \mathrm{AgCl}$ (3.0 M KCl). Cyclic voltammetry was typically performed from -0.2 to $+1.0 \mathrm{~V}$ at $5 \mathrm{mV} / \mathrm{s}$. AFM characterization was performed using a JPK NanoWizard 3 set-up. AC-non contact mode (tapping mode) measurements were carried out with silicon ACTA-50 tips with cantilever length $125 \mu \mathrm{m}$, spring constant $\sim 40 \mathrm{~N} / \mathrm{m}$, and resonance frequency $\sim 300 \mathrm{kHz}$.

Scanning electron microscopy (SEM) was performed with Quanta $200 \mathrm{~F}$ FEG-SEM from FEI (USA) to have a complete overview of the thiol-modified surfaces before and after dealloying. Energy dispersive X-ray (EDX) spectra were taken with high-resolution field emission instrument Nova Nano SEMEDX 450, FEI (USA) on different parts of each sample after dealloying to estimate the surface chemical composition. FIB-SEM was performed after dealloying by using dual-beam focused ion beam instruments Helios NanoLab G3 CX and SCIOS, FEI (USA).

\section{Molecular dynamics simulations}

Molecular dynamics simulations were performed for $A u(111)$ and an area of $\sim 360 \times 28 \AA^{2}$ with periodicity in the shortest direction (y in the plots). Simulations were performed with NAMD $^{29}$. The CHARMM force-field was used to describe the octadecanethiol molecules; parameters were previously optimized by performing a full ab-initio minimization. Octadecanethiol molecules were deposited vertically on the surface with 
different densities and left to evolve during $1 \mathrm{~ns}$. Intermolecular van der Waals interactions were modeled with a Lennard-Jones potential.

\section{DATA AVAILABILITY}

Supplementary material is available. Other relevant data are also available from the corresponding and first author of this paper upon a reasonable request.

Received: 19 October 2020; Accepted: 13 April 2021; Published online: 27 May 2021

\section{REFERENCES}

1. Maurice, V. \& Marcus, P. Progress in corrosion science at atomic and nanometric scales. Prog. Mater. Sci. 95, 132-171 (2018).

2. Vericat, C., Vela, M. E., Benitez, G., Carro, P. \& Salvarezza, R. C. Self-assembled monolayers of thiols and dithiols on gold: new challenges for a well-known system. Chem. Soc. Rev. 39, 1805-1834 (2010).

3. Laibinis, P. E. \& Whitesides, G. M. Self-assembled monolayers of $\mathrm{N}$-alkanethiolates on copper are barrier films that protect the metal against oxidation by air. J. Am. Chem. Soc. 114, 9022-9028 (1992).

4. Belarbi, Z., Singer, M., Farelas, F. \& Young, D. Thiols as volatile corrosion inhibitors for top of the line corrosion. Corrosion 73, 892-899 (2017).

5. Mekhalif, Z., Riga, J., Pireaux, J.-J. \& Delhalle, J. Self-assembled monolayers of ndodecanethiol on electrochemically modified polycrystalline nickel surfaces. Langmuir 13, 2285-2290 (1998).

6. Renner, F. U. et al. Star-shaped crystallographic cracking of localized nanoporous defects. Adv. Mater. 27, 4877-4882 (2015).

7. Frankel, G. S. Pitting corrosion of metals a review of the critical factors. J. Electrochem. Soc. 145, 2186-2198 (1998).

8. Moffat, T. P., Fan, F. R. F. \& Bard, A. J. Electrochemical and scanning tunneling microscopic study of dealloying of $\mathrm{Cu}_{3} \mathrm{Au}$. J. Electrochem. Soc. 138, 3224-3235 (1991).

9. Erlebacher, J., Aziz, M. J., Karma, A., Dimitrov, N. \& Sieradzki, K. Evolution of nanoporosity in dealloying. Nature 410, 5-8 (2001).

10. Pickering, H. W. \& Wagner, C. Electrolytic dissolution of binary alloys containing a noble metal. J. Electrochem. Soc. 114, 698-706 (1967).

11. Sieradzki, K. \& Newman, R. C. Brittle behavior of ductile metals during stresscorrosion cracking. Philosop. Mag. A 51, 95-132 (1985).

12. Renner, F. U. et al. Initial corrosion observed on the atomic scale. Nature 439, 707-710 (2006).

13. Wittstock, A., Biener, J. \& Bäumer, M. Nanoporous gold: a new material for catalytic and sensor applications. Phys. Chem. Chem. Phys. 12, 12919-12930 (2010).

14. Parida, S. et al. Volume change during the formation of nanoporous gold by dealloying. Phys. Rev. Lett. 97, 503-505 (2006).

15. Pareek, A. et al. Initiation and inhibition of dealloying of single crystalline $\mathrm{Cu}_{3} \mathrm{Au}$ (111) surfaces. J. Am. Chem. Soc. 133, 18264-18271 (2011).

16. Love, J. C., Estroff, L. A., Kriebel, J. K., Nuzzo, R. G. \& Whitesides, G. M. Selfassembled monolayers of thiolates on metals as a form of nanotechnology. Chem. Rev. 105, 1103-1169 (2005).

17. Whitesides, G. M., Kriebel, J. K. \& Love, J. C. Molecular engineering of surfaces using self-assembled monolayers. Sci. Prog. 88, 17-48 (2005).

18. Wilbur, B. J. L., Kumar, A., Kim, E. \& Whitesides, G. M. Microfabrication by microcontact printing of self-assembled monolayers. Adv. Mater. 6, 600-604 (1994).

19. Uddin, M. J. et al. Time and pressure dependent deformation of microcontact printed channels fabricated using selfassembled monolayers of alkanethiol on gold. J. Sci. Adv. Mater. Devices 2, 385-391 (2017).

20. Kumar, A., Abbott, N. L., Kim, E., Biebuyck, H. A. \& Whitesides, G. M. Patterned selfassembled monolayers and meso-scale phenomena. Chem. Res 28, 219-226 (1995).

21. Neupane, S. et al. Two-step nanoscale approach for well-defined complex alkanethiol films on Au surfaces. Langmuir 34, 66-72 (2018).

22. Ankah, G. N., Pareek, A., Cherevko, S., Zegenhagen, J. \& Renner, F. U. Hierarchical nanoporous films obtained by surface cracking on $\mathrm{Cu}-\mathrm{Au}$ and ethanethiol on $\mathrm{Au}$ (001). Electrochim. Acta 140, 352-358 (2014).

23. Pareek, A. et al. Effect of thiol self-assembled monolayers and plasma polymer films on dealloying of Cu-Au alloys. RSC Adv. 3, 6586-6595 (2013).

24. Larsen, N. B., Biebuyck, H., Delamarche, E. \& Michel, B. Order in microcontact printed self-assembled monolayers. J. Am. Chem. Soc. 119, 3017-3026 (1997).
25. Lis, D. et al. Self-assembled film organization in fast microcontact printing investigated by sum frequency generation spectroscopy. J. Phys. Chem. C. 113, 9857-9864 (2009).

26. Zhu, Y., Free, M. L., Woolam, R. \& Durnie, W. A review of surfactants as corrosion inhibitors and associated modeling. Prog. Mater. Sci. 90, 159-223 (2017).

27. Valtiner, M., Ankah, G. N., Bashir, A. \& Renner, F. U. Atomic force microscope imaging and force measurements at electrified and actively corroding interfaces: challenges and novel cell design. Rev. Sci. Instrum. 82, 023703 (2011).

28. Hassel, A. W., Fushimi, K. \& Masahiro, S. An agar-based silver-silver chloride reference electrode for use in micro-electrochemistry. Electrochem. Comm. 1, 180-183 (1999).

29. James, C. et al. Scalable molecular dynamics with NAMD. J. Comput. Chem. 26, 1781-1802 (2005).

\section{ACKNOWLEDGEMENTS}

Financial support by FWO Odysseus program under the G0D0115N project is appreciated. We acknowledge the support of FWO for the joint-focused ion beam (FIB) facility for nanofabrication and nanocharacterization (AKUL-15-22). We also thank for support via the M-era.Net project CoinDesc. This project has received technical support from the EU-H2020 research and innovation program under grant agreement No. 654360 , Nanoscience Foundries, and Fine Analysis (NFFA). We acknowledge the use of the FIB dual-beam instrument granted by BMBF under grant no. 5K13WC3 (PT-DESY). At UPC, we acknowledge MINECO projects PCIN-2016-027 and FIS2017-82625-P.

\section{AUTHOR CONTRIBUTIONS}

S.N., P.L.P. and F.U.R. performed the AFM experiments. N.R., J.D. and T.F.K. provided SEM and FIB-SEM images. Samples have been prepared by S.N., T.F.K., H.N., A.S. and P.L.P.; M.R. and A.T. provided the PDMS stamps and guided us through its application. F.U.R. conceived and designed the experiments. O.B., D.C., A.K. and F.U.R. designed the simulation approach. O.B. and D.C. performed molecular dynamics simulations. S.N. and F.U.R. provided the first draft of the manuscript; all authors analyzed the data, discussed the results, co-wrote the paper, and commented on the manuscript.

\section{COMPETING INTERESTS}

The authors declare no competing interests.

\section{ADDITIONAL INFORMATION}

Supplementary information The online version contains supplementary material available at https://doi.org/10.1038/s41529-021-00169-2.

Correspondence and requests for materials should be addressed to F.U.R.

Reprints and permission information is available at http://www.nature.com/reprints

Publisher's note Springer Nature remains neutral with regard to jurisdictional claims in published maps and institutional affiliations.

(i) Open Access This article is licensed under a Creative Commons adaptation, distribution and reproduction in any medium or format, as long as you give appropriate credit to the original author(s) and the source, provide a link to the Creative Commons license, and indicate if changes were made. The images or other third party material in this article are included in the article's Creative Commons license, unless indicated otherwise in a credit line to the material. If material is not included in the article's Creative Commons license and your intended use is not permitted by statutory regulation or exceeds the permitted use, you will need to obtain permission directly from the copyright holder. To view a copy of this license, visit http://creativecommons. org/licenses/by/4.0/.

(c) The Author(s) 2021 